\title{
Serenoa repens and its effects on male sexual function. A systematic review and meta-analysis of clinical trials
}

\author{
Gianni Paulis ${ }^{1}$, Andrea Paulis ${ }^{2}$, Gianpaolo Perletti ${ }^{3,4}$ \\ ${ }^{1}$ Department of Uro-Andrology, Castelfidardo Medical Team, Rome, Italy; \\ ${ }^{2}$ Neurosystem Center for applied Psychology and Neuroscience, Janet Clinical Centre, Rome, Italy; \\ ${ }^{3}$ Department of Biotechnology and Life Sciences, Section of Medical and Surgical Sciences, University of Insubria, Varese, Italy; \\ ${ }^{4}$ Faculty of Medicine and Medical Sciences, Ghent University, Belgium.
}

\begin{abstract}
Summary Background: Serenoa repens (SR) is a plant used to treat benign prostatic hyperplasia and prostatitis. We know that SR act as a $5 \alpha$-reductase inhibitor, moreover, several studies have proved that SR has anti-inflammatory and antioxidant properties. There is some belief among patients that SR may negatively impact male sexual function. Such belief is circulating in non-medical social networks and is perhaps maintained by patients as a result of incorrect web surfing. However, it is also possible that SR may exert a "nocebo" effect thus negatively impacting on the general well-being of patients.

Objective: The aim of this study is to investigate whether SR is causing negative effects on male sexual function.

Methods: To ascertain the effect of SR on male sexual function, we conducted a systematic review and meta-analysis, by performing an electronic database search in accordance with the PRISMA guidelines.

Results: Out of 20 included papers, 8 papers reported comparisons of SR with placebo, and 7 studies reported comparisons of $S R$ with tamsulosin. The standardized mean difference of changes from baseline scores of sexual function was not signifcantly different between SR and placebo (SMD: 0.43, 95\% CI: 0.18 to $1.05 ; I^{\wedge} 2=95 \%$ ). Similarly, no significant mean differences in the Male Sexual Function-4 (MSF-4) test scores were found between SR and tamsulosin (SMD: $-0.31,95 \%$ CI: -0.82 to $\left.0.19 ; I^{\wedge} 2=90 \%\right)$.

Conclusions: We found no statistically significant differences between negative effects on sexual function in patients treated with SR compared to patients who received placebo. The results of our meta-analysis are similar to those of other systematic reviews. Studies are warranted to ascertain whether any such effects might occur as a result of a nocebo effect.
\end{abstract}

KEY WORDS: Serenoa repens; Adverse effects; Nocebo effect; Male sexual health.

Submitted 30 November 2021; Accepted 3 December 2021

\section{INTRODUCTION}

Serenoa repens (SR), also known as Saw palmetto, Sabal serrulata, and American dwarf palm tree, is a plant originally used by Native Americans (Seminole and Miccosukee tribes) both as food and to cure urogenital ailments (1). The plant belongs to the Arecaceae family and mainly grows in the southern United States, particularly in Florida and South Carolina (2). SR is commonly used throughout the world to treat benign prostatic hyperplasia (BPH) and prostatitis. Although its mechanism of action has not fully been demonstrated yet, it is mainly used on the assumption that SR is a $5 \alpha$-reductase inhibitor, consequently blocking the conversion of testosterone to dihydrotestosterone (DHT) a biologically more active hormone $(2,3)$. In the literature, however, several studies have proved that $\mathrm{SR}$, besides being very selective for the prostate gland, has, above all, pro-apoptotic, anti-inflammatory, and antioxidant properties (4-21). Normally used SR doses vary between 320 and $450 \mathrm{mg} /$ day.

The aim of this study is to clarify whether SR is able to cause negative effects on male sexual function. Such belief is circulating in non-medical social networks and is maintained by patients as a result of web surfing. Not infrequently, even in our clinics, we encounter patients suffering from BPH or prostatitis who underwent treatment of varying length with SR, who claim to have noticed a significant reduction in their erectile potency, and in some cases even in their libido. Many web forums in the world discuss the alleged negative effects of SR, equating them directly to the post-finasteride syndrome; unfortunately, once pseudo-confirmation is found by surfing the net, a belief quickly and easily goes viral. Is it possible that SR may have a nocebo effect and therefore negatively impact the health of patients, regardless of any real pharmacological adverse effect (22)?

The aim of this work was to assess whether SR can cause negative effects on male sexual function. We therefore carried out an in-depth systematic review and metaanalysis in accordance with the PRISMA guidelines (23).

\section{MATERIALS AND METHOdS}

This review was conducted in accordance with the Preferred Reporting Items for Systematic Reviews and MetaAnalyses (PRISMA) guidelines (23). The review protocol was submitted for registration on the PROSPERO platform (ID 287140). Two electronic databases (PubMed and EMBASE) were searched for articles published up to 30 September 2021. The search was performed using the following terms: (Serenoa repens OR Saw palmetto OR Sabal

\footnotetext{
No conflict of interest declared.
} 
serrulata) AND (Orgasm OR Ejaculation OR Erectile dysfunction OR sexual dysfunction, physiological). Relevant data were also hand-searched through other sources.

We considered randomized controlled trials (RCTs) with an open-label or single/double blinded design published in English without time constraints.

We included studies involving male subjects taking Serenoa repens extracts to treat a prostatic condition, compared with placebo, or with various drugs prescribed for benign prostatic hyperplasia (BPH) (e.g., alpha adrenoceptor blockers, alpha-reductase inhibitors).

The following outcomes were considered: (i) the rate of sexual dysfunction (erectile dysfunction, ejaculatory dysfunction, dysorgasmia, loss of libido), and/or the changes of scores of questionnaires measuring sexual function. The Brief Male Sexual Function Inventory (BMSFI) is a questionnaire to measure male sexual function covering sexual drive (two items), erection (three items), ejaculation (two items), perceptions of problems in each area (three items), and overall satisfaction (one item) (24).

The International Index of Erectile Function (IIEF) is a 15item questionnaire addressing five relevant domains of male sexual function (erectile function, orgasmic function, sexual desire, intercourse satisfaction, and overall satisfaction) (25). An abridged, five-item version of the IIEF-5 can also be administered for the evaluation of erectile dysfunction (26).

Increasing severity of sexual function is associated with lower scores of BMSFI and IIEF. The Male Sexual Function-
4 item (MSF-4) questionnaire is a concise survey evaluating four items (interest in sex, quality of erection, achievement of ejaculation, and achievement of orgasm). Lower scores of this instrument are associated with better preserved sexual function (27).

Two independent authors performed title and abstract screening of all retrieved records to delete duplicates and to exclude reports that did not meet the inclusion criteria. A second round of full-text screening to confirm/exclude the inclusion of retrieved studies and to extract relevant information was performed by 2 authors using a standardized form.

The publication bias was assessed in the presence of at least 5 trials. It was analyzed by visually inspecting funnel plots and by performing the Egger's and Begg's tests using the MetaEssentials 1 software (Rotterdam School of Management, Erasmus University, The Netherlands).

Statistical analysis was performed using the RevMan5 software. Meta-analysis was performed using a random effects model. Dichotomous data (presence/absence of sexual dysfunction) or continuous data reporting changes of mean values of sexual function scores and number of per-protocol or intent-to-treat patients were extracted.

For dichotomous data we calculated odds ratios (OR), for continuous data presented as pre-vs. post-therapy mean differences, we calculated inverse variance weighted standardized mean differences. For all analyses we calculated 95\% confidence intervals (CI). Heterogeneity was assessed by calculating the $\mathrm{I}^{\wedge} 2$ value with $95 \% \mathrm{CIs}$, and interpreted as follows: $0 \%$ to $40 \%$ : might not be important; 30\% to $60 \%$ : may represent moderate heterogeneity; $50 \%$ to $90 \%$ : may represent substantial heterogeneity; $75 \%$ to $100 \%$ : considerable heterogeneity.

A summary of findings table was generated, and the quality of the evidence emerging from meta-analyses including at least 3 studies was rated according to GRADE criteria.

\section{RESULTS}

A PRISMA flow diagram illustrates the results of the study selection process (see Figure 1). We retrieved 29 papers: 7 papers from PubMed, 17 papers from EMBASE and 5 from other sources (handsearching). Four duplicate papers were removed, and 5 papers were excluded as they were found to be not related to this review.

Figure 1.

A PRISMA flow diagram. 


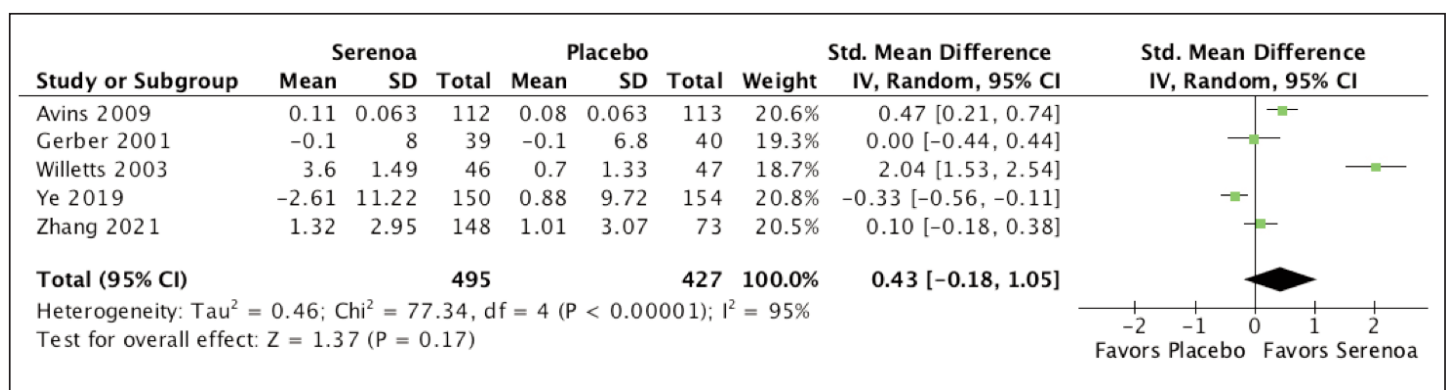

\begin{tabular}{|c|c|c|c|c|c|c|c|c|c|}
\hline Study or Subgroup & \multicolumn{3}{|c|}{ Serenoa } & \multicolumn{3}{|c|}{ Tamsulosin } & \multicolumn{2}{|c|}{ Std. Mean Difference } & $\begin{array}{l}\text { Std. Mean Difference } \\
\text { IV, Random, } 95 \% \mathrm{CI}\end{array}$ \\
\hline De Bruyne 2002 & 0.5 & 3.3 & 267 & 0.4 & 3.5 & 266 & $35.8 \%$ & $0.03[-0.14,0.20]$ & \\
\hline Latil 2015 & 0.36 & 0.35 & 83 & 0.64 & 0.35 & 86 & $32.6 \%$ & $-0.80[-1.11,-0.48]$ & - \\
\hline Total $(95 \% \mathrm{Cl})$ & & & 415 & & & 411 & $100.0 \%$ & $-0.31[-0.82,0.19]$ & \\
\hline
\end{tabular}

\begin{tabular}{|c|c|c|c|c|c|c|c|c|}
\hline \multirow{2}{*}{$\begin{array}{l}\text { Study or Subgroup } \\
\text { De Bruyne } 2004\end{array}$} & \multicolumn{2}{|c|}{ Serenoa } & $\begin{array}{l}\text { Tamsul } \\
\text { Events }\end{array}$ & $\begin{array}{l}\text { osin } \\
\text { Total }\end{array}$ & Weight & $\begin{array}{c}\text { Odds Ratio } \\
\text { M-H, Random, } 95 \% \mathrm{Cl}\end{array}$ & \multicolumn{2}{|c|}{\begin{tabular}{c}
\multicolumn{1}{c}{ Odds Ratio } \\
M-H, Random, $95 \% \mathrm{Cl}$ \\
\end{tabular}} \\
\hline & 0 & 65 & 1 & 59 & $45.5 \%$ & $0.30[0.01,7.45]$ & $\square$ & + \\
\hline Hizli 2007 & 0 & 20 & 7 & 20 & $54.5 \%$ & $0.04[0.00,0.83]$ & & \\
\hline Total $(95 \% \mathrm{Cl})$ & & 85 & & 79 & $100.0 \%$ & $0.10[0.01,0.92]$ & & \\
\hline \multirow{2}{*}{\multicolumn{7}{|c|}{$\begin{array}{l}\text { Total events } \\
\text { Heterogeneity: } \mathrm{Tau}^{2}=0.00 ; \mathrm{Chi}^{2}=0.76, \mathrm{df}=1(\mathrm{P}=0.38) ; \mathrm{I}^{2}=0 \% \\
\text { Test for overall effect: } \mathrm{Z}=2.03(\mathrm{P}=0.04)\end{array}$}} & & \\
\hline & & & & & & & $\begin{array}{lll}0.001 & 0.1 & 1 \\
\text { Favours } & \text { Serenoa }\end{array}$ & $10 \frac{1000}{\text { Favours Tamsulosin }}$ \\
\hline
\end{tabular}

Figure 2.

Statistical analysis: differences in sexual dysfunction between treatment with Serenoa repens and placebo.

Figure 3. Statistical analysis: differences in the MSF-4 test scores between treatment with Serenoa repens and Tamsulosin.

Figure 4.

Statistical analysis: ejaculatory disorders after treatment with Serenoa repens and Tamsulosin.
Out of the 20 remaining papers, we selected 8 papers reporting comparisons of SR with placebo. Three records were discarded after full-text reading (two were lacking information on sexual outcomes and one reported only information on sexual hormones).

Other 7 studies reported comparisons of SR with tamsulosin. Two studies were excluded because Serenoa repens was administered in association with other herbal products and one because SR was administered in combination with tamsulosin versus tamsulosin alone.

Two studies compared SR with finasteride; one was excluded because SR was administered in combination with other herbal products.

Three studies compared a SR extract with other herbal products. Two were discarded because of lack of information on sexual function and one because SR was administered in a formulation containing other herbal products.

The characteristics of the 10 studies finally included in this systematic review, and the evaluation of risk of bias are presented in the "Supplementary Materials".

Quantitative analysis was limited to five studies comparing therapy with a SR extract with placebo, and to four studies comparing a SR extract with tamsulosin (28-36). A study comparing a SR extract with finasteride was only qualitatively evaluated (37).

To evaluate differences in sexual dysfunction between treatment arms we calculated standardized mean differ- ences, as included trials used different sexual function scales. The standardized mean difference of changes from baseline scores was not significantly different between SR and placebo (SMD: 0.43, 95\% CI: -0.18 to $1.05 ; 5$ trials, 922 patients; $\mathrm{Z}=1.37, \mathrm{P}=0.17$; Egger's $\mathrm{P}=0.16$; Begg's $\mathrm{P}=0.32$ ). This analysis was characterized by considerable heterogeneity ( $\mathrm{I}^{\wedge} 2=95 \%$ ) (Figure 2 ).

No significant mean differences in the MSF-4 test scores were found between SR and tamsulosin (SMD: -0.31, 95\% CI: -0.82 to $0.19 ; 3$ trials, 826 patients; $Z=1.21$, $\mathrm{P}$ $=0.22 ; \mathrm{I}^{\wedge} 2=90 \%$ ) (Figure 3 ).

However, random-effects meta-analysis revealed that treatment with SR is associated with significantly lower odds of ejaculatory disorders compared to tamsulosin (odds ratio $=0.10,95 \% \mathrm{CI}: 0.01$ to $0.92 ; 2$ trials, 164 participants, $\mathrm{Z}=2.03, \mathrm{P}=0.04, \mathrm{I}^{\wedge} 2=0 \%$ ), compared to placebo (see Figure 4) $(34,35)$.

Final results are reported in Table 1.

\section{Discussion}

Although the quality of evidence grade of our meta-analysis is low (see Table 1), we found no statistically significant differences between negative effects on sexual function in patients treated with SR compared to patients who received placebo or tamsulosin.

This suggests that SR does not appear produce negative 
Table 1.

Summary of findings.

\begin{tabular}{|c|c|c|c|}
\hline \multicolumn{4}{|c|}{ Serenoa repens compared with placebo or active drug (Tamsulosin) } \\
\hline \multicolumn{4}{|c|}{$\begin{array}{l}\text { Patient or population: Patients with Benign Prostatic Hyperplasia } \\
\text { Settings: Outpatient } \\
\text { Intervention: Serenoa repens extract } \\
\text { Comparators: Placebo or active comparator (alpha adrenoceptor blocker) }\end{array}$} \\
\hline Outcomes & $\begin{array}{l}\text { Intervention vs. } \\
\text { comparator results }\end{array}$ & $\begin{array}{l}\text { Number of participants } \\
\text { (studies) }\end{array}$ & $\begin{array}{l}\text { Quality of the evidence } \\
\text { (grade) }\end{array}$ \\
\hline $\begin{array}{l}\text { Sexual (dys)function, SD units } \\
\text { [assessed using different sexual function scales] }\end{array}$ & $\begin{array}{l}\text { The sexual function score in the Serenoa repens } \\
\text { groups was on average } 0.43 \text { SDs ( } 95 \% \text { Cl: }-0.18 \text { to } 1.05 \text { ) } \\
\text { higher than in the placebo groups. }\end{array}$ & $\begin{array}{l}922 \\
(5)\end{array}$ & $\begin{array}{l}\oplus \oplus \odot \odot \\
\text { low } \\
\text { Reasons for downgrading: } \\
\text { - Inconsistency (considerable heterogeneity) } \\
\text { - Indirectness (subjectiveness) of evidences }\end{array}$ \\
\hline $\begin{array}{l}\text { Sexual (dys)function, SD units } \\
\text { [assessed using the Male Sexual Function 4-items test] }\end{array}$ & $\begin{array}{l}\text { The score of the MSF- } 4 \text { test in the } \\
\text { tamsulosin groups was on average } \\
0.31 \text { SDs ( } 95 \% \text { Cl: }-0.82 \text { to } 0.19) \\
\text { lower than in the Serenoa repens groups. }\end{array}$ & $\begin{array}{l}826 \\
(3)\end{array}$ & $\begin{array}{l}\oplus \oplus \odot \odot \\
\text { low } \\
\text { Reasons for downgrading: } \\
\text { - Inconsistency (considerable heterogeneity) } \\
\text { - Indirectness (subjectiveness) of evidence }\end{array}$ \\
\hline \multicolumn{4}{|c|}{$\begin{array}{l}\text { SD: Standard deviation; Cl: Confidence interval; MSF-4: Male Sexual Function 4-items test. } \\
\text { GRADE Working Group grades of evidence. } \\
\text { High quality: Further research is very unlikely to change our confidence in the estimate of effect. } \\
\text { Moderate quality: Further research is likely to have an important impact on our confidence in the estimate of effect and may change the estimate. } \\
\text { Low quality: Further research is very likely to have an important impact on our confidence in the estimate of effect and is likely to change the estimate. } \\
\text { Very low quality: We are very uncertain about the estimate. }\end{array}$} \\
\hline
\end{tabular}

effects on male sexual function. Such view is supported by two studies (Marks et al., 2000; Pytel et al., 2002) which did not detect a reduction in the serum levels of male sex hormones (testosterone, dihydrotestosterone) after treatment with SR $(38,39)$.

The results of our meta-analysis are similar to those of other authoritative systematic reviews, where SR was proved to have no negative impact on male sexual function (40-42).

It should furthermore be evaluated whether the negative effect of SR on male sexuality reported by a number of patients both in our clinics and on Internet forums may be generated by neuropsychological mechanisms. This is where the concept of nocebo comes in. A nocebo effect is generated when a patient's beliefs and negative expectations cause a worsening of the individual's health status (22). The psychological mechanisms underlying this pesky effect seem to include negative expectations concerning treatment, high levels of anxiety, and classic conditioning (43). A study by Mondaini et al. (2007) provides a very interesting analysis of the causal role of "negative expectations" on the nocebo effect, after patient have been informed of the possible side effects of a therapeutic substance (44). In this study, which included 107 patients suffering from BPH, two treatment groups were created, with finasteride $5 \mathrm{mg} /$ day and a treatment length of 12 months. Patients of Group 1 (52 patients) were also not informed of the risk of side effects on their sexuality; patients of Group 2, instead, were told of the possible albeit rare - onset of sexual problems such as erectile dysfunction (ED), decreased libido, and ejaculation disorders. The results, after treatment with finasteride 5 $\mathrm{mg}$ /day for 12 months, were the following: Group 1, adverse sexual side effects $15.3 \%$ (ED 9.6\%, decreased libido 7.7\%, ejaculation disorders 5.7\%); Group 2, adverse sexual side effects $43.6 \%$ (ED 30.9\%, decreased libido $23.6 \%$, ejaculation disorders $16.3 \%$ ). The signifi- cantly higher rate of sexual dysfunctions in Group 2 compared to Group 1 clearly proves that the nocebo effect had a significant impact on the greater number of occurrences of sexual problems in the patients of Group 2 (44). It is possible that SR may also have a "nocebo" effect and therefore negatively impact the health of patients.

\section{Conclusions}

Based on the results of our review, SR does not appear to cause negative effects on male sexuality; should any such effects occur, they may be ascribed to a nocebo effect.

Adequately powered studies are needed to confirm this hypothesis. In such a case to reduce the likelihood of a nocebo effect, when mentioning possible side effects during the informed consent process prior to treatment, it may be necessary to structure the information to patients by avoiding the classic "negative" narrative frame (percentage of possibility of having a specific side effect), employing instead a "positive" approach, providing information about the percentage of patients who are likely not to experience any side effects.

A more in-depth knowledge of the mechanisms that cause the nocebo effect, will help to minimize its impact in the clinical activity of general practitioners and specialists alike.

\section{ACKNOWLEDGMENTS}

We thank dr. Pasquale Del Vecchio for bibliometric and data management analysis.

\section{REFERENCES}

1. Bennet BC, Hicklin JR. Uses of saw palmetto (Serenoa repens, Arecaceae) in Florida. Economic Botany. 1998; 52:381-393.

2. Duborija-Kovacevic N, Jakovljevic V, Sabo A, et al. Tolerability 
and toxicity of lipidosterolic extract of American dwarf palm Serenoa repens in Wistar rats: well-known extract, new insight. Eur Rev Med Pharmacol Sci. 2011; 15:1311-1317.

3. Bayne CW, Donnelly $F$, Ross $M$, et al. Serenoa repens (Permixon ${ }^{\circledR}$ ): A 5areductase types I and II inhibitor-new evidence in a coculture model of BPH. Prostate. 1999; 40:232-241.

4. Habib FK. Serenoa repens: the scientific basis for the treatment of benign prostatic hyperplasia. Eur Urol Suppl. 2009; 8:887-893.

5. McNicholas TA, Kirby RS, Lepor H. Evaluation and nonsurgical management of benign prostatic hyperplasia. In: Wein AJ, Kavoussi LR, Novick AC, Partin AW, Peters CA, editors. Campbell-Walsh Urology.

6. Paubert-Braquet M, Mencia Huerta JMM, Cousse H, et al. Effect of the lipidic lipidosterolic extract of Serenoa repens (Permixon ${ }^{\circledR}$ ) on the ionophore A23187-stimulated production of leukotriene B4 (LTB4) from human polymorphonuclear neutrophils. Prostaglandins Leukot Essent Fatty Acids. 1997; 57:299-304.

7. Colado-Velázquez J, Mailloux-Salinas P, Medina-Contreras JML, et al. Effect of Serenoa repens on oxidative stress, inflammatory and growth factors in obese wistar rats with benign prostatic hyperplasia. Phytother Res. 2015;29:1525-1531.

8. Latil A, Pétrissans MT, Rouquet J, et al. Effects of hexanic extract of Serenoa repens (Permixon ${ }^{\circledR} 160 \mathrm{mg}$ ) on inflammation biomarkers in the treatment of lower urinary tract symptoms related to benign prostatic hyperplasia. Prostate. 2015; 75:1857-1867.

9. Vela Navarrete R, Garcia Cardoso JG, Barat A, et al. BPH and inflammation: pharmacological effects of permixon on histological and molecular inflammatory markers. Results of a double blind pilot clinical assay. Eur Urol. 2003; 44:549-555.

10. Morgia G, Cimino S, Favilla V, et al. Effects of Serenoa repens, selenium and lycopene (Profluss ${ }^{\circledR}$ ) on chronic inflammation associated with benign prostatic hyperplasia: results of FLOG (Flogosis and Profluss in Prostatic and Genital Disease), a Multicentre Italian Study. Int Braz J Urol. 2013; 39:214-221.

11. Park EJ, Kim SA, Choi YM, et al. Capric acid inhibits NO production and STAT3 activation during LPS-induced osteoclastogenesis. PLoS One. 2011; 6:e27739.

12. Kim HJ, Yoon HJ, Kim SY, et al. A medium-chain fatty acid, capric acid, inhibits RANKL-induced osteoclast differentiation via the suppression of NF-KB signaling and blocks cytoskeletal organization and survival in mature osteoclasts. Mol Cells. 2014; 37:598-604.

13. Henry GE, Momin RA, Nair MG, et al. Antioxidant and cyclooxygenase activities of fatty acids found in food. J Agric Food Chem. 2002; 50:2231-2234.

14. Hoshimoto A, Suzuki Y, Katsuno T, et al. Caprylic acid and medium-chain triglycerides inhibit IL-8 gene transcription in Caco-2 cells: comparison with the potent histone deacetylase inhibitor trichostatin A. Br J Pharmacol. 2002; 136:280-286.

15. Srivastava A, Rao LJM, Shivanandappa T. 14-Aminotetradecanoic acid exhibits antioxidant activity and ameliorates xenobiotics-induced cytotoxicity. Mol Cell Biochem. 2012; 364:1-9.

16. Oh YT, Lee JY, Lee J, et al. Oleic acid reduces lipopolysaccharideinduced expression of iNOS and COX-2 in BV2 murine microglial cells: possible involvement of reactive oxygen species, p38 MAPK, and IKK/NF-kappaB signaling pathways. Neurosci Lett. 2009; 464:93-97.

17. Ambrozova G, Pekarova M, Lojek A. Effect of polyunsaturated fatty acids on the reactive oxygen and nitrogen species production by raw 264.7 macrophages. Eur J Nutr. 2010; 49:133-139.
18. Ren J, Chung SH. Anti-inflammatory effect of $\boldsymbol{\alpha}$-linolenic acid and its mode of action through the inhibition of nitric oxide production and inducible nitric oxide synthase gene expression via NF-KB and mitogen-activated protein kinase pathways. J Agric Food Chem. 2007; 55:5073-5080.

19. Olennikov DN, Zilfikarov IN, Khodakova SE. Phenolic compounds from Serenoa repens fruit. Chem Nat Compd. 2013; 49:526529.

20. Cristoni A, Di Pierro F, Bombardelli E. Botanical derivatives for the prostate. Fitoterapia. 2000; 71:S21-S28.

21. Nickel JC. Shoskes D, Roehrborn CG, et al. Nutraceuticals in prostate disease: the urologist's role. Rev Urol. 2008; 10:192-206.

22. Požgain I, Požgain Z, Degmecic D. Placebo and nocebo effect: a mini-review. Psychiatr Danub. 2014; 26:0-107.

23. Moher D, Liberati A, Tetzlaff J, Altman DG, The PRISMA Group. Preferred Reporting Items for Systematic Reviews and MetaAnalyses: The PRISMA Statement. PLoS Med. 2009: 6:e1000097.

24. O'Leary MP, Fowler FJ, Lenderking WR, et al. A brief male sexual function inventory for urology. Urology. 1995; 46:697-706.

25. Rosen RC, Riley A, Wagner $G$, et al. The international index of erectile function (IIEF): a multidimensional scale for assessment of erectile dysfunction. Urology. 1997; 49:822-830.

26. Rosen RC, Cappelleri JC, Smith MD, et al. Development and evaluation of an abridged, 5-item version of the International Index of Erectile Function (IIEF-5) as a diagnostic tool for erectile dysfunction. Int J Impot Res. 1999; 11:319-326.

27. Marquis $P$, Marrel, A. Reproducibility and clinical and concurrent validity of the MSF-4: a four-item male sexual function questionnaire for patients with benign prostatic hyperplasia. Value Health. 2001; 4:335-343.

28. Avins AL, Bent S, Staccone $S$, et al. A detailed safety assessment of a saw palmetto extract. Complement Ther Med. 2008; 16:147154.

29. Gerber GS, Kuznetsov D, Johnson BC, et al. Randomized, double-blind, placebo-controlled trial of saw palmetto in men with lower urinary tract symptoms. Urology. 2001; 58:960-963.

30. Willetts KE, Clements MS, Champion S, et al. Serenoa repens extract for benign prostate hyperplasia: a randomized controlled trial. BJU Int. 2003; 92:267-70.

31. Ye Z, Huang J, Zhou L, et al. Efficacy and safety of Serenoa repens extract among patients with benign prostatic hyperplasia in China: a multicenter, randomized, double-blind, placebo-controlled trial. Urology. 2019; 129:172-179.

32. Zhang K, Guo RQ, Chen SW, et al. The efficacy and safety of Serenoa repens extract for the treatment of patients with chronic prostatitis/chronic pelvic pain syndrome: a multicenter, randomized, double-blind, placebo-controlled trial. World J Urol. 2021; 1-7.

33. Debruyne F, Koch G, Boyle P, et al. Comparison of a phytotherapeutic agent (Permixon) with an $\alpha$-blocker (tamsulosin) in the treatment of benign prostatic hyperplasia: a 1-year randomized international study. Eur Urol. 2002; 41:497-506.

34. Debruyne F, Boyle P, Calais Da Silva F, et al. Evaluation of the clinical benefit of permixon and tamsulosin in severe BPH patients PERMAL study subset analysis Eur Urol. 2004; 45:773-780.

35. Hizli F, Uygur MC. A prospective study of the efficacy of Serenoa repens, tamsulosin, and Serenoa repens plus tamsulosin treatment for patients with benign prostate hyperplasia. Int Urol Nephrol. 2007; 39:879-886 
36. Latil A, Pétrissans MT, Rouquet J, et al. Effects of hexanic extract of Serenoa repens (Permixon ${ }^{\circledR} 160 \mathrm{mg}$ ) on inflammation biomarkers in the treatment of lower urinary tract symptoms related to benign prostatic hyperplasia. Prostate. 2015; 75:1857-1867.

37. Carraro JC, Raynaud JP, Koch G, et al. Comparison of phytotherapy (Permixon ${ }^{\circledR}$ ) with finasteride in the treatment of benign prostate hyperplasia: a randomized international study of 1,098 patients. Prostate. 1996; 29:231-240.

38. Marks LS, Partin AW, Epstein JI, et al. Effects of a saw palmetto herbal blend in men with symptomatic benign prostatic hyperplasia. J Urol. 2000; 163:1451-1456.

39. Pytel YA, Vinarov A, Lopatkin N. et al. Long-term clinical and biologic effects of the lipidosterolic extract of Serenoa repens in patients with symptomatic benign prostatic hyperplasia. Adv Ther. 2002; 19:297-306.

40. Vela-Navarrete $R$, Alcaraz A, Rodríguez-Antolín A, et al. Efficacy and safety of a hexanic extract of Serenoa repens $\left(\right.$ Permixon $\left.{ }^{\circledR}\right)$ for the treatment of lower urinary tract symptoms asso- ciated with benign prostatic hyperplasia (LUTS/BPH): systematic review and meta-analysis of randomised controlled trials and observational studies. BJU Int. 2018; 122:1049-1065.

41. Novara G, Giannarini G, Alcaraz A, et al. Efficacy and safety of hexanic lipidosterolic extract of Serenoa repens (Permixon) in the treatment of lower urinary tract symptoms due to benign prostatic hyperplasia: systematic review and meta-analysis of randomized controlled trials. Euro Urol Focus. 2016; 2:553-561.

42. Cai T, Cui Y, Yu S, et al. Comparison of Serenoa repens With Tamsulosin in the Treatment of Benign Prostatic Hyperplasia: A Systematic Review and Meta-Analysis. Am J Mens Health. 2020; 14 : 1557988320905407

43. Colloca L, Barsky AJ. Placebo and nocebo effects. N Engl J Med. 2020; 382:554-561.

44. Mondaini N, Gontero P, Giubilei G, et al. Finasteride $5 \mathrm{mg}$ and sexual side effects: how many of these are related to a nocebo phenomenon?. J Sex Med, 2007; 4:1708-1712.

\section{Correspondence}

Gianni Paulis, MD (Corresponding Author)

paulisg@libero.it

Department of Uro-Andrology, Castelfidardo Medical Team, Rome (Italy)

Andrea Paulis, Clinical Psychologist

andrea.fx.94@gmail.com

Neurosystem Center for applied Psychology and Neuroscience, Janet

Clinical Centre, Rome (Italy)

Gianpaolo Perletti, PhD

gianpaolo.perletti@uninsubria.it

Department of Biotechnology and Life Sciences, Section of Medical

and Surgical Sciences, University of Insubria, Varese (Italy) 